\title{
Spontaneous emission of laser dye molecules in syn- thetic opals under conditions of low dielectric contrast
}

\author{
Moiseyenko V.N., Dergachov M.P., Shvachich V.G., \\ Shvets T.V. and Roshchenko O.F. \\ Oles’ Honchar Dnipropetrovsk National University, 72 Gagarin Ave., \\ 49010 Dnipropetrovsk, Ukraine, e-mail: vnmois@yandex.ru
}

Received: 04.07.2009

\begin{abstract}
Spontaneous emission of laser dye molecules (rhodamine 6G and pironin G) embedded into pores of synthetic opal photonic crystals is studied in the spectral region of 520-650 nm. It is ascertained that the emission spectra are greatly dependent on the photonic stop-band position and the spectral distribution of photon density of states. A dependence of spectral position of the emission band from the dielectric contrast is found.
\end{abstract}

PACS: $78.67-\mathrm{n}, 78.55 . \mathrm{Mb}$

UDC: 535.361

Keywords: laser dye molecules, fluorescence spectra, photon density of states, low dielectric contrast

\section{Introduction}

Photonic crystals as materials with forbidden bands in their photonic band structure are now under extensive study because of possibilities for managing spontaneous emission in quite easy ways [1-3]. Spontaneous emission of light sources embedded in the photonic crystals is completely inhibited in the spectral range corresponding to photonic band gap and it can be strongly modified by a spectral distribution of photon density of states (DOS). Since its prediction, this effect has been repeatedly proved in many experimental works devoted to studies of emission of molecules included into pores of photonic crystals [4-7]. As a good prototype of 3D photonic crystals, synthetic opals made of $\mathrm{SiO}_{2}$ globules with a diameter close to the light wavelength have been used widely [8]. They are characterised by a stop-band in the <111> direction and a singular behaviour of DOS nearby the band edges.

The purpose of the present work is to study fluorescence spectra of rhodamine $6 \mathrm{G}$ (R6G) and pironin $\mathrm{G}(\mathrm{PG})$ molecules embedded in the synthetic opals under conditions of low dielectric contrast.

\section{Samples and experimental setup}

Dimensions of globular $\mathrm{SiO}_{2}$ synthetic opals used in these studies were about $1.0 \times 1.0 \times 0.1 \mathrm{~cm}^{3}$. Characterisation of opals was performed by measuring the optical transmission spectra. The synthetic opal photonic crystals (SOPC) were doped with R6G

Ukr. J. Phys. Opt. 2010, V11, №1 
and PG molecules by soaking samples in a dilute ethanol solution $\left(\sim 10^{-4} \mathrm{M}\right)$. The concentration of laser dye molecules in the solution was kept low to prevent light reabsorption and nonradiative transfer effects. After evaporating ethanol, the fluorescence spectra were measured. In order to study the fluorescence under low dielectric contrast conditions the SOPC samples were soaked in various water-glycerine solutions with R6G and PG molecules.

The fluorescence of laser dye molecules was excited with a radiation of LED Edixeon EDST-3LAx (the wavelength of $\lambda_{e x}=517 \mathrm{~nm}$ and the average power of $30 \mathrm{~mW}$ ). The spectra were measured in the "reflection geometry" for the samples infiltrated with R6G molecules and in the "transmission geometry" for those infiltrated with PG ones. Spectral analysis of the emission was performed with a modernised spectrometer DFS-12. The spectra were detected within the aperture of $\leq 0.17 \pi \mathrm{sr}$ in the $\langle 111\rangle$ direction. Useful signals were detected in a regime of photon counting with accumulation. Finally, a spectral distribution in the emission spectra was corrected by subtracting the spectrum of exciting radiation.

\section{Results and interpretation}

The fluorescence spectra are shown in Fig. 1 and Fig. 2. As seen from Fig. 1, a partial inhibition of fluorescence intensity takes place within a region corresponding to the stop-band for both molecules embedded in SOPC after ethanol evaporating. For the R6G spectrum, enhancement of the short-wavelength tail of the emission band is observed, while the long-wavelength tail of the fluorescence spectrum is not altered essentially (see Fig. 1a). At the same time, the spectrum of PG in the SOPC is concentrated inside a longwavelength region though it is rather not amplified (see curve 2 in Fig. 1b).

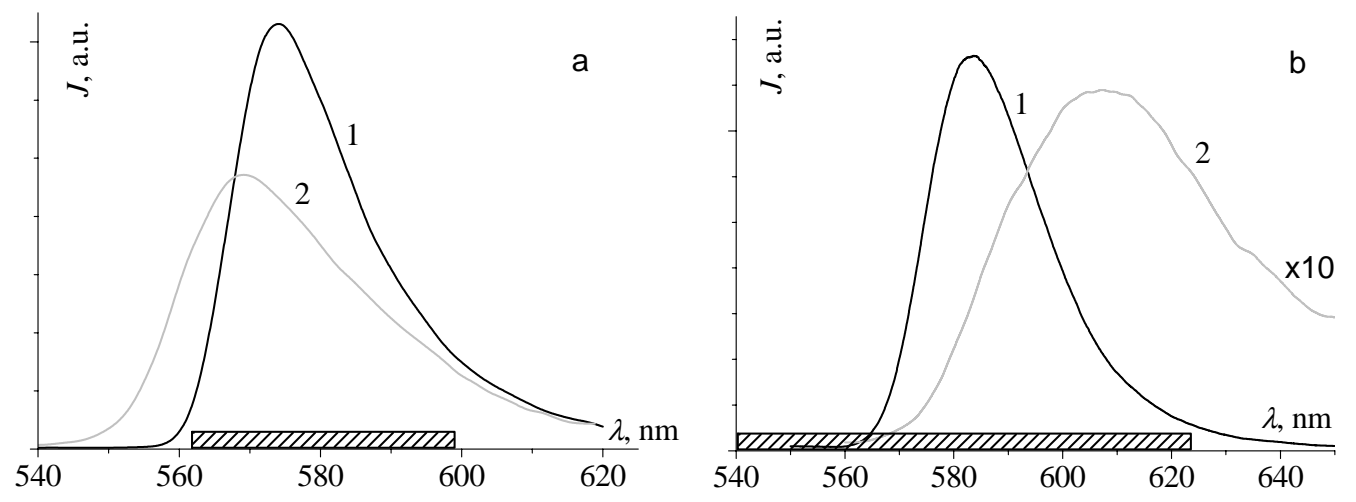

Fig. 1. Fluorescence spectra of $R 6 G(a)$ and $P G(b)$ in the ethanol solution placed in the optical cell (curve 1) and in the SOPC (curve 2). The rectangles point to the SOPC stop-band position.

Following the work [6], the transformations observed above may be explained in the following way. When the emission light with the wavelength $\left(\lambda_{e m}\right)$ shorter than the stopband centre one $\left(\lambda_{c}\right)$ is emitted in the $\langle 111\rangle$ direction it encounters Bragg diffraction at higher angles. Because of diffuse propagation more light is detected in the $\langle 111\rangle$ direc- 
tion at these high angles. For the light of any longer wavelengths $\left(\lambda_{e m}>\lambda_{c}\right)$ all the directions in sample volume are equivalent and that light escapes the sample without being enhanced. Besides, the spectral distribution of the spontaneous emission is determined by the photon DOS [2]. Therefore, the emission maximum position should be correlated with the DOS maximum. In both cases (see curves 2 in Fig. 1a and Fig. 1b) the spectral intensity maximum is situated in the vicinity of the stop-band edge which is correspondent to the DOS maximum. The absence of total fluorescence inhibition inside the stop-band region can be connected with the structure disorder that results in appearance of local states in the stop-band [9].
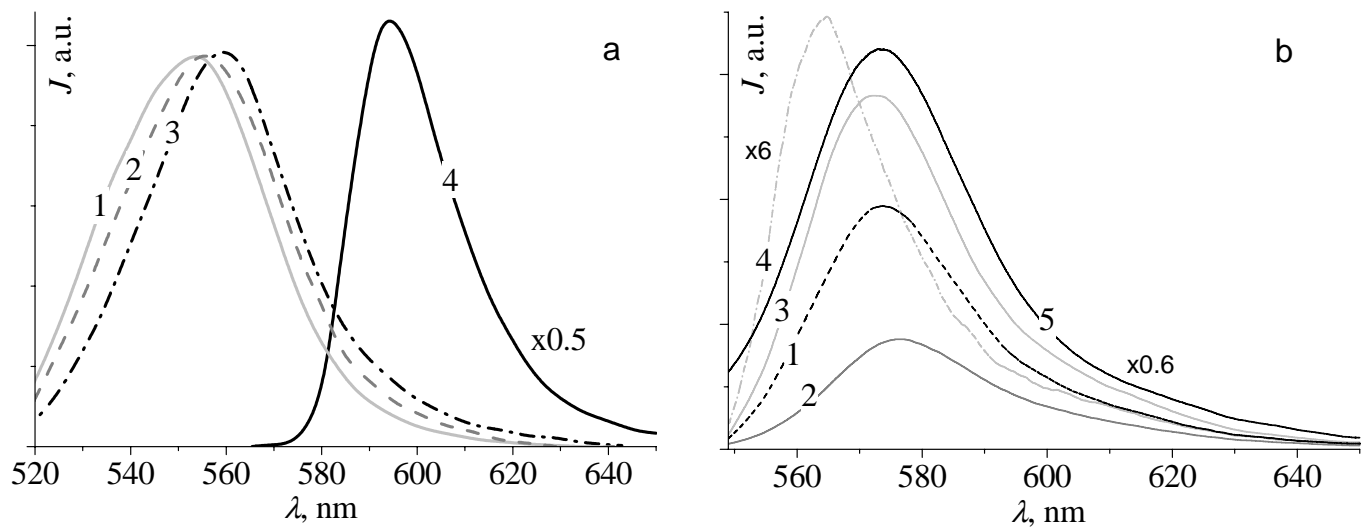

Fig. 2. Fluorescence spectra of R6G (a) and $P G(b)$ in the SOPC infiltrated with a water-glycerine solution (a) for the volume glycerine concentrations of $66 \%$ (curve 1), $75 \%$ (2), 100\% (3) and in the pure glycerine placed in the optical cell (4); (b) the same spectra for $40 \%(1), 60 \%(2), 80 \%(3), 100 \%(4)$ and for the case of pure glycerine placed in the optical cell (5).

From these points of view the spectral distribution of the fluorescence bands of R6G and PG at various glycerine concentrations (Fig. 2) may be interpreted as follows. Opal infiltration with any water-glycerine solution yields in decreasing dielectric contrast in the SOPC volume as the refractive index of the water-glycerine solution $n_{p}$ (variable from 1.39227 till 1.47399 in our experiments) is close to that of $\mathrm{SiO}_{2}$ globules $\left(n_{S}=1.47\right)$. It causes a shift of the stop-band centre $\lambda_{c}$ to longer wavelengths $\left(\lambda_{c}(\theta)=2 d \sqrt{n_{e f f}^{2}-\sin ^{2} \theta}\right)$ and a narrowing of the stop-band $\Delta \lambda_{g}$ with increasing the glycerine concentration $C_{g l}$. The corresponding relation is represented by $\Delta \lambda_{g} \approx \frac{2}{\pi} \lambda_{c} \frac{\Delta n}{n}$ [10], where $n_{\text {eff }}^{2}=0.74 n_{S}^{2}+0.26 n_{p}^{2}$ with assumption of full occupation of pores with glycerine, $\Delta n=\left|n_{S}-n_{p}\right|, n=n_{\text {eff }}$ in our case, $\theta$ denotes the incident angle, and $d$ the distance between the (111) planes. According to our calculations, the centres of photonic stop-band in the samples with R6G molecules are located at 621,623 and $627 \mathrm{~nm}$ for the glycerine concentrations being equal to $66 \%$, $75 \%$ and $100 \%$, respectively. Thus, the maximum shift of the stop-band centre amounts 
to $6 \mathrm{~nm}$. It corresponds exactly to the fluorescence maximum shift observed by us for the R6G (Fig. 2a).

In case of the PG molecules, we have somewhat different behaviour (see Fig. $2 \mathrm{~b}$ and Fig. 3). In the absence of solution the condition $\lambda_{e m}>\lambda_{c}$ takes place and we have a weak emission in the long-wavelength region mentioned above.

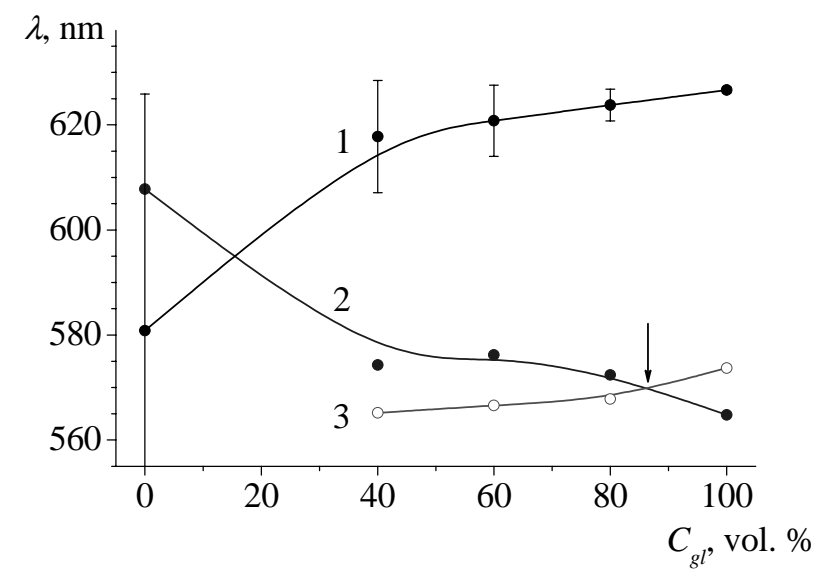

Fig. 3. Concentration dependences of the stop-band centre $\lambda_{c}$ (curve 1), the fluorescence band maximum of PG in the SOPC (curve 2) and in the waterglycerine solution placed in the optical cell (curve 3). Bars indicate the stopband width $\Delta \Lambda_{g}$.

As the glycerine concentration increases, the relation between $\lambda_{e m}$ and $\lambda_{c}$ becomes the opposite $\left(\lambda_{e m}<\lambda_{c}\right)$ and the short-wavelength tail of the fluorescence band is being enhanced. At the glycerine concentrations close to 85 volume \% (marked by arrow in Fig. 3), the dielectric contrast vanishes $\left(\Delta \lambda_{g}=0\right)$ and the fluorescence band position becomes just the same as in the optical cell (a so-called solvent effect). After passing through this point, the stop-band width $\Delta \lambda_{g}$ starts growing due to increasing refractive index $n_{p}$. In this case we have an inversion of the photonic bands, something like that occurring in the narrow-gap semiconductors. The fluorescence band in such the inverse SOPC is shifting towards a 'blue' side (see curve 4 in Fig. $2 b$ and curve 2 in Fig. 3).

\section{Conclusion}

The emission spectra of the R6G and PG molecules embedded into pores of the synthetic opals have been studied under conditions of low dielectric contrast. For the both laser dye molecules the emission inhibition has occurred within the spectral region of the stopband, whereas the emission intensity increase has been observed nearby the stop-band edges. The shift of the emission spectrum of R6G and PG in the synthetic opal is determined by the relation between the maximum fluorescence wavelength and the spectral centre of the stop-band. The 'blue' shift of the fluorescence spectrum of PG has been observed for the sample infiltrated with pure glycerine. 


\section{References}

1. Bykov V P, 1972. Spontaneous emission in a periodic structure. Sov. Phys. JETP 35: 269-273.

2. Yablonovitch E, 1987. Inhibited spontaneous emission in solid-state physics and electronics. Phys. Rev. Lett. 58: 2059-2062.

3. John S, 1987. Strong localization of photons in certain disordered dielectric superlattices. Phys. Rev. Lett. 58: 2486-2489.

4. Gaponenko S V, Bogomolov V N, Petrov E P, Kapitonov A M, Eychmuller A A, Rogach I I, Gindele F and Woggon U, 2000. Spontaneous emission of organic molecules and semiconductor nanocrystals in a photonic crystal. J. Lumin. 87-89: 152156.

5. Romanov S G and Fokin A V, 2003. Variation of spontaneous emission in the opal stop-band with an enhanced refractive-index contrast. Phys. of the Solid State. 45: 1090-6460.

6. Bechger L, Lodahl P and Vos W L, 2005. Directional fluorescence spectra of laser dye in opal and inverse opal photonic crystals. J. Phys. Chem. B. 109: 9980-9988.

7. Emelchenko G A, Gruzincev A N, Kovalchuk M N, Maslov V M, Samarov E N, Yakimov E E, Barthou C and Zverkova I I, 2005. Opal-ZnO nanocomposites: structure and emission properties. Fiz. Tekhn. Poluprov. 39: 1375-1379.

8. Gorelik V S, 2007. Optics of globular photonic crystals. Kvant. Elektron. 37: 409432.

9. Kaliteevskii M A, Nikolaev V V and Abram R A, 2005. Eigenstate statistics and optical properties of one-dimensional disordered photonic crystals. Phys. of the Solid State. 47: 1948-1957.

10. Yariv A and Yeh P, Optical waves in crystals. Mir: Moscow (1984).

Moiseyenko V.N., Dergachov M.P., Shvachich V.G., Shvets T.V. and Roshchenko O.F., 2010. Spontaneous emission of laser dye molecules in synthetic opals under conditions of low dielectric contrast. Ukr.J.Phys.Opt. 11: 1-5.

\footnotetext{
Анотація. В спектральній області 520-650 нм досліджено спонтанне випромінювання молекул лазерних барвників (родамін $6 G$ і піронін $G$ ), введених у пори фотонних кристалів на основі синтетичних опалів. Встановлено, що спектр випромінювання суттєво залежить від положення стоп-зони і спектрального розподілу густини фотонних станів. Виявлена залежність спектрального положення смуги випромінювання від діелектричного контрасту.
} 